Rev. Latinoam. Psicopat. Fund., São Paulo, 20(1), 194-196, mar. 2017 http://dx.doi.org/10.1590/1415-4714.2017v20n1p194-13.

Del don de amor al objeto a: Deuda versus intercambio

Manuel Coloma Arenas

Buenos Aires: Letra Viva, 2015, 300 págs

\title{
Un objeto múltiple para el psicoanálisis
}

\author{
Cristóbal Durán Rojas*1
}

Este libro posee varias virtudes. Algunas de ellas saltarán a la vista de forma inmediata: un manejo certero y contundente de las nociones y del aparato terminológico que recorren los escritos y seminarios de Jacques Lacan, la exposición problemática de recursos temáticos que a primera vista parecen excéntricos al corpus lacaniano, y la fuerza para ligar discusiones y referencias heterogéneas, como aquellas del psicoanálisis, la antropología o la filosofía. Sin embargo, hay una virtud que sobresale, y que persiste como una de las hipótesis que marcan con más fuerza la novedad de este libro.

El autor construye su argumento sobre la base de un encuentro, que se revela inmensamente productivo, entre la obra de conjunto de Jacques Lacan y El Anti-Edipo, trabajo publicado en 1972 por Gilles Deleuze y Félix Guattari. Si bien es riguroso al momento de mostrar las relaciones que se entrecruzan en el psicoanálisis propuesto por Lacan - Freud, evidentemente, pero también Lévi-Strauss, Bataille e Nietzsche, por mencionar sólo a algunos - , este libro se detiene en la obra de Deleuze y Guattari, tradicionalmente concebida como una de las más opuestas a la enseñanza lacaniana. Dicho encuentro - un 'encuentro impensado',

\footnotetext{
${ }^{* 1}$ Universidad Andrés Bello (Santiago, Chile).
} 


\section{RESENHAS BIBLIOGRÁFICAS}

como el mismo autor lo denomina - con el libro que a primera vista parece un mero antagonista, se planteará como fundamental para exponer la singular invención del objeto $a$, entendido como un objeto que "responde a una identidad radical del sujeto" (p. 20).

Sin ir más lejos, El anti-Edipo es, según el autor, "un texto lacaniano, lleno de una serie de conceptos esparcidos a lo largo de los seminarios de Lacan" (p. 137). Este encuentro articula explícitamente el concepto clínico de una identidad resultante de una alienación fundamental con la descodificación de los flujos que recorren el campo social, tal como Deleuze y Guattari la definieron a lo largo de sus escritos. En esa articulación, la lectura de Coloma intenta mostrar que ese encuentro agrega un potencial teórico a las relaciones entre la comprensión clínica lacaniana y el campo social. Dicho potencial se muestra especialmente a la hora de discutir el lugar del objeto $a$ : lejos de codificar los flujos de deseo y encadenar las formas de filiación, dicho objeto permite pensar formas de relatividad perpetua, en una "no-relación radical" (p. 148), donde los objetos que el deseo pone en circulación son mantenidos en una variación continua e infinita.

La lectura de este encuentro propuesta por el autor modifica la comprensión de una serie de términos del léxico lacaniano, y contribuye a perfilar sus alcances de una manera novedosa. Ese sería el caso, entre otros, de la noción lacaniana de falta, que articula la relación del sujeto con su deseo, y que según este nuevo prisma podría referir a "una positividad que responde más bien a la dimensión de la desmesura" (p. 115). De un modo similar, el carácter excesivo de la estructuración subjetiva se hace patente al momento de considerar el concepto de amor propuesto por Lacan. Si amar es 'dar lo que no se tiene', ello no tiene que ser reducido a constatar una falta o una imposibilidad del objeto amoroso. Antes que eso, se trata de enfatizar el carácter múltiple y diverso con el cual se podría entender la posibilidad de un objeto. Con ello, se descubren otras vías de acceso que fomentan una intelección más plural y polifacética del objeto descrito por el psicoanálisis.

El estatuto del objeto así considerado depende de cierta desposesión subjetiva, indispensable para comprender que el deseo que lo persigue nunca se guía sencillamente por personas o funciones discernibles, sino por variaciones intensivas que definen el lugar de un sujeto policéfalo o acéfalo que describió Lacan, y que éste mismo reconoce como la multitud freudiana (p. 219). En esta medida, el examen propuesto por Coloma aproxima las elaboraciones clínicas de Lacan a la comprensión deleuziana-guattariana de una multiplicidad impersonal que alimenta a toda subjetividad in statu nascendi. 


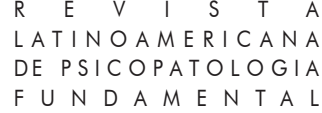

Esta particular lectura, no está de más recordarlo, abre una veta relevante, cuya ganancia no es sólo el enriquecimiento mutuo de perspectivas teóricas que han sido pensadas en su pura divergencia, sino sobre todo en su contribución para pensar los alcances clínicos de un inconsciente que resiste a la idea de identidad y de unidad. En este sentido, quizá uno de los mayores aportes de este trabajo resida en recordarnos, explícitamente, que es perfectamente posible y necesario aprender a leer un deseo no edipizado en el texto lacaniano. Un deseo así, que circula tras un objeto inobjetivable, anticipa en gran medida la idea misma de 'máquina deseante' de Deleuze y Guattari, y perfila un objeto que desmonta las relaciones de filiación y pertenencia, movilizando el deseo más allá de sus supuestos esquemas de fijación. Ese último sería un claro ejemplo de aquello que constituye el mayor aporte transversal que propone el libro de Coloma: afirmarnos enfáticamente que la construcción de la teoría y de la clínica psicoanalítica tiene que estar siempre atenta a las variaciones de una subjetividad que se encuentra en proceso de constitución y a unos objetos de deseo que son siempre plurales y singulares, como la propia experiencia con la que el psicoanálisis plantea su marca distintiva.

196 Citação/Citation: Rojas, C. D. (2017, março). Un objeto múltiple para el psicoanálisis. Resenha do livro Del don de amor al objeto a: Deuda versus intercambio. Revista Latinoamericana de Psicopatologia Fundamental, 20(1), 194-196.

Editores do artigo/Editors: Profa. Dra. Sonia Leite

Recebido/Received: 15.10.2016 / 10.15.2016 Aceito/Accepted: 8.12.2016 / 12.8.2016

Copyright: (C) 2009 Associação Universitária de Pesquisa em Psicopatologia Fundamental/ University Association for Research in Fundamental Psychopathology. Este é um artigo de livre acesso, que permite uso irrestrito, distribuição e reprodução em qualquer meio, desde que $\mathrm{o}$ autor e a fonte sejam citados / This is an open-access article, which permits unrestricted use, distribution, and reproduction in any medium, provided the original authors and sources are credited.

\section{Cristóbal Durán Rojas}

Académico Doctorado en Psicoanálisis, Facultad de Humanidades y Ciencias Sociales, Universidad Andrés Bello (Santiago, Chile).

Dublé Almeyda 3274, dpto. 302

(7750000 Ñuñoa, Santiago, Chile)

cristobaldr@gmail.com

This is an open-access article, which permits unrestricted use, distribution, and reproduction in any medium for non-commercial purposes provided the original authors and sources are credited. 